\title{
HOW INDIAN NEWSROOMS POD: STUDYING THE PRACTICES OF JOURNALISTIC PODCASTING IN INDIA
}

\author{
Sneha Gore Mehendale* \\ Symbiosis Institute of Media and Communication, \\ Symbiosis International University, Pune, India \\ +91- 9049877977, sneha.mehendale@simc.edu \\ Nilesh Gokhale \\ Symbiosis Institute of Media and Communication, \\ Symbiosis International University, Pune, India
}

\begin{abstract}
The modern digital newsrooms produce journalistic output in multiple new content formats, podcasting being one of them. This study presents different contours of podcasting as practised in the Indian newsrooms through the study of journalistic practices associated with it. Based on fieldwork in newsrooms as well as in-depth interviews, the study tells that the news selection practices for podcasting show a different set of news values emerging. The role of audience in podcast production as well as the headlining function was also examined. The journalists were found to employ a more interpretive, narrative style of storytelling, moving away from the old journalistic norm of objectivity. Furthermore, these journalists were found to understand podcasting as a form of 'slow journalism' and consciously employing the slow techniques in their practice, conceptualizing podcasts as a necessary break in the modern day news work that is 'always on'.
\end{abstract}

Key words:, Journalistic Practices, News Selection, News Production, News podcasting, Podcasting.

\section{INTRODUCTION}

It has been a while since the 'new media' stopped being new. Much like other aspects of life, digital has become default even in the context of media. Journalism is no exception, since it is being shaped greatly by the digital technologies, and every smaller piece in the bigger puzzle of practice is re-aligned in this era different from what it was. (Steensen \& Westlund, 2020) The news production is always on, the advertising revenues seem to be sinking, news outlets are in search of newer business models and audiences have become extremely important (Deuze \& Witschge, 2018). Reuters Institute, in their report state how news organizations today employ various techniques to negotiate with these changing surroundings, like going behind pay walls or introducing new content formats. These formats are many, ranging from listicles to VR videos. (Newman et al, 2017). One of the increasingly popular content formats amongst these is that of podcasting. (Newman \& Gallo, 2019)

The Cambridge dictionary defines podcasting as audio files being disseminated over the internet which could be downloaded and listened to at the users' end. While the origins of podcasting date back to 2004, it is the arrival of an American podcast named 'serial' in 2014 which is considered as a watershed moment in its trajectory. (Berry, 2015) Like the global numbers, the Indian media audiences too consistently show a rising trend of listenership. India is the world's third-largest podcast listening market at 57 million listeners as of 2020 (PriceWaterhouseCoopers, 2020). The global pandemic situation has also recently boosted the consumption of podcasts, reported the Economic times. (Mandavia, 2020) Apart from listening, the production of podcasts has grown too in the past several years, with many Indian news media organizations launching their own podcasts. (Zompa, 2021) Journalistic podcasting seems to be gaining ground in India, however, academic studies examining the practice of podcasting remain scarce. Academic literature surveyed below also highlights this gap, where practitioners' lenses for journalistic podcasting have not been adopted. This study attempts filling this gap, and to that end, asks the following questions: 
What are the news selection and production practices of journalistic podcasting in the Indian newsrooms?

\section{LITERATURE REVIEW}

\subsection{Journalism studies of the past}

The understanding of what journalism means initially seemed somewhat uniform across the world, with a clearly identified set of values, principles and practices enacted in a certain way. (Deuze \& Witschge, 2018). As Zelizer (2004) points out, there have been more or less coherent conceptualizations of what journalism means and what journalists do. Hallin (1992) very aptly calls it a sense of 'wholeness and seamlessness'. The profession gets associated with a specific occupational ideology and culture. The 'universal notion of journalism' (Haniztsch, 2007) is still seen prevalent in many journalists as well journalism academics. A lot of seminal work from the past, exploring various themes like news values for the news selection (Galtung \& Ruge, 1965) Gatekeeping (Manning-White, 1950) journalistic routines in news production (Turnstall, 1971;Tuchman, 1978) the hierarchy of influences (Shoemaker \& Reese, 1996) the professional or occupational ideology (Schlesinger, 1978; Golding, 1979) or the political economy perspective (Herman \& Chomsky, 1989), focussed on print media and legacy newsrooms. Moreover, they mostly operate on this Universalist notion of journalism by studying or acknowledging routine, patterned ways of doing journalism.

\subsection{Journalism in 'flux'}

The emergence of new technologies in this millennium has caused fundamental changes in the journalism field. Emergence of web 2.0 based technologies facilitated the interaction between the journalist and audience. This transformed the audiences from their passive role into a tremendously active role and these 'people formerly known as audience' (Rosen, 2012) started playing a greater role in news production. Due to the penetration of social media, the news dissemination channels became multifold. Business models of the print-dominated legacy media era toppled in the wake of all of this. Journalism industry finds itself in a 'flux' today. Journalism academia was quick to take a note of it with different conceptualizations of journalism coming up. Hermida (2010) proposed 'ambient journalism', which offers 'diverse means to collect, communicate, share and display news and information'. Anderson (2011) advocated a concept of 'blown-up newsroom', where the news production transcends the boundaries of the traditional newsroom and newer actors of journalism come into play. Along the same lines, Hermida (2019) advocates that the practices and processes making up journalism take place in novel spaces, in novel ways outside of the institutional confines of cathedrals of the profession'. Taking all of this into account, the ontological position of the current journalism industry needs to be rearticulated. Mark Deuze (2018) therefore suggests considering journalism as a constantly 'under process' phenomenon than a robust structure that has well defined elements. Deuze proposes to look 'beyond journalism', and looking at it as a set of institutional practices.

\subsection{Journalism practices}

Journalistic practices are integrally tied to the technologies available to and leveraged by practicing actors (Barnard, 2016). The work of journalists has changed considerably since the proliferation of digital media technologies. It gets manifested in the journalistic practices of identifying, producing, distributing, and responding to news (Barnard, 2016).

Practice is a polysemic concept and it is essential to define what practice means for the scope of this study. Schatzki et al (2001) argued that practices are centrally organized around shared practical understanding. The classic journalistic practices of selecting, producing and disseminating the news are all a result of a shared understanding and actions driven by that understanding. This highlights the two interlinked levels of any practice- the activity and the discourse surrounding that activity- or simply, the 'saying' and the 'doing'. (Witschge \& Harbers (2018) support this thought when they argue that one can view the practices of journalism as a set of activities and shared understanding of what journalism is. How journalistic practices are shaped is a complex question. It may be partially a result of age-old conventions, coupled with newer technologies, changing business models and the subjective experiences of the practising journalist. Hence even while looking at practices; it is advisable to avoid either a socially deterministic or technologically deterministic view, since both 
social and technological factors affect the enactment of understanding.

In its simplest form, journalism consists of regular core practices of selection, production and distribution of previously unknown information. (Raetzsch, 2015). However, as mentioned above, these core practices are currently not only happening much more diverse settings, but are also enacted by increasingly varying actors. A major reason behind this would be the digitalization of communication technologies and the emergence of new user cultures.

Gherardi (2009) says that practices are regular patterns of actions that embody and reiterate shared conceptions of that activity, thereby sustaining the practice. Since the practice is enacted in a light of shared understanding, the understanding of an 'ideal' way of performing a practice differs between those who do it, especially during a period of change. As news professionals are experimenting with new formats and genres revolving around convergence, multimedia reporting, and audience participation in a networked media environment (Spyridou et al, 2013) studying the practices associated with the new formats and environment becomes far more important.

\subsection{Journalistic practices in the new age}

Choosing a particular piece of information to be made into a news story is one of the most crucial practices for a journalist. Selecting only a handful of news stories to be covered and published was the decision of a gatekeeper (Manning-White, 1950), based on certain news values. (Galtung \& Ruge, 1965) Although in its modern form, 'what will work on social media' and 'what will the audience click on' are possibly the most important news values for any journalist. (Anderson, 2011; Vu, 2014; Harcup \& O'Neil, 2017).

The consumption of news on digital platforms is continuously increasing. The change in the medium of consumption has also had a change in the ways newsrooms work as well as the norms of journalism. With shorter production cycles, the news production is 'always on' and blurs the pre-existing content formats (Saltzis, 2012). Digital news formats increasingly feature content that seems to be going away from the traditional journalism norm of objectivity and embracing a more 'personal' (Coward, 2013) way of journalism. The availability of audience data is another fundamental change in the whole journalism ecosystem that directly affects the journalistic practice. (Neheli, 2018; Karlsson, et al., 2018) The journalistic authority is often questioned due to the audience data (Coddington, 2019) and creating content only for the so-called audience engagement (Nelson, 2019) or the elusive 'clicks' (Anderson, 2011) may be seen.

\subsection{Podcasting and journalism}

In its early days, podcasting has often been explained with radio as a reference point. The scholarly conceptualization of podcasting has however moved away from radio, and considers podcasting as "a set of specific practices and cultural meanings that are entirely entwined with the technologies for its distribution, organization, and consumption." (Morris \& patterson, 2015; Berry, 2016) For newsrooms or for the journalists, podcasting is a format where 'journalistic rigor is being combined with freedom in ways we haven't considered before' (Larson, 2015). Extending the thought, Mia Lindgren (Lindgren, 2016) puts forth how the format of podcasting encourages an emerging genre of personal narrative journalism. The 'intimate' nature of this medium seems to be fostering the usage for featuring personal narratives. A ReutersOxford study (Newman \& Gallo, 2019) makes a strong case for podcasting being considered as a legitimate content format for journalism, as observed amongst top media publishing outlets across the world. And while podcasts will not totally replace the currently existing news formats, they appear to expand the reach of journalism (Nee \& Santana, 2021) and hence deserve academic enquiry.

It is worth noting that any journalistic practice is not medium or platform agnostic. Digital innovations can potentially change journalism practices (Santana \& Dozier, 2019). As new content formats are introduced due to changing technology and new actors emerge in the field, the practice may be enacted in a different manner. Podcasts are no exception to this, since they represent a new turn of audio journalism. In light of this, looking at journalistic practices of this rapidly developing new journalism format becomes important. 


\section{FRAMEWORK FOR THE STUDY}

This study works with the changed ontological position of journalism, where it is looked at as an 'ongoing' phenomenon than static. (Deuze, 2018) Additionally, it employs a social constructivist epistemological approach, where the study aims at looking at how journalism is 'constructed, maintained and eventually changed' (Domingo et al, 2014). Considering these particular ontological and epistemological positions, the study uses Schatzki's (2001) practice theory.

The notion of adopting the 'practice' lens to understand journalism has been around since quite some time. (Zelizer, 2004; Couldry, 2004) Although it needs to be understood that it is not a homogenous, unified theory. It has multiple separate strands that allow us to understand journalism as an ongoing and reciprocal exchange of activities involved and hence is particularly well suited to study the journalism 'in flux'. As mentioned before, the practices have two levels- that of actual physical manifestation of activity and that of the understanding of that activity. This entwined nature of the 'saying' and 'doing' levels also brings about a need to study the practices bottom up. Gherardi (2009) points out that any practice is never a result of a systematic top-down approach where absolutely rational knowledge and goals are translated into clearly delineated practice. Bottom up approach gives the researcher an option to collect various examples of practices and present them rather than being fixated with one notion of 'the' journalistic practice, which anyway prove counterintuitive to the 'liquid' state of journalism.

The study focuses on two classic journalistic practices- of news selection and news production- and aims to study how they pan out with reference to journalistic podcasting.

\section{METHODOLOGY}

As guided by the practice theory approach, the researcher used participant observations in a newsroom as well as in depth interviews with the podcasting journalists. Participant observation helps in understanding the 'everydayness' of any practice by situating the ongoing activity in context of its environmental features (McLess, 2013). Here, it helped in witnessing the naturally occurring behaviour of podcasting journalists in their usual professional contexts. In depth interviews guided the researcher about the personal experiences, thoughts and understanding that journalists have of their own practice.

\section{Sampling}

This study uses the non-probability technique of purposive sampling. After checking for Indian news outlets (both from legacy media as well as digital-only news outlets) that produce podcasts, three newsrooms were finalized. They were moneycontrol.com (a business and finance website belonging to one of the largest media conglomerates, Network18), the Hindu (one of the oldest Indian dailies) and BBC Marathi (a digitalonly platform of the regional service of the $\mathrm{BBC})$.

The researcher spent 29 hours over three days in the moneycontrol newsroom for participant observations as well as in-depth interviews. Due to the pandemic-imposed restrictions since March 2020, journalists from the remaining two newsrooms could not be met and observed in person, but telephonic indepth interviews were conducted with journalists from the Hindu's Chennai newsroom and the BBC Marathi's Delhi newsroom. Data collection happened between December 2019 and December 2020. All interviews were recorded and transcribed in order to analyse.

\section{RESULTS AND DISCUSSION}

\subsection{News selection:}

As mentioned in the literature review above, the understanding of news values today is primarily driven by the audience's reception of and subsequent action taken with reference to content. The study sample was also no exception to it. It was observed that the podcasting journalists' team spent a lot of time in brainstorming the topics and discussing whether and how will they work on social media. This discussion though is more than guesswork. The BBC team specifically said that they are constantly 'listening in' on social networks and following the day's trending themes as well as words. Based on this intelligence, they choose the information or topics that align with the trends. However, the selection possibility based on a 'culture of the click' (Anderson, 2011) is limited in a sense since a robust mechanism for podcast specific 
audience data is still not widely available. The social media engagement also usually indicates at the possible number of actual listens of a podcast. But it can at best be a gauging tool since there is no correlation between these two data points. Neither can be a determining factor or a measure of the other.

"We get our numbers of listens, region wise break up and other stuff. But we do not have the competitor's data. So we have no way of knowing if Quint's podcast on the same topic got so many clicks, and if that is more or less, so there is no external reference point to compare. Amongst our own podcasts, we know what gets consumed the most. But getting informed about competitors performance is crucial, since it completes the picture", says a journalist from the moneycontrol team. Here, the shared understanding of the podcasting journalists about digital journalism being driven by the 'culture of the click' does not endorse what literature would have one believe.

'High shelf-life' and 'conversability' were two more news values emerging. As podcasts listening defies the space-time logic, the audience may listen to a podcast not immediately but a week after it was published. Choosing 'evergreen' topics for podcasting is an option. But podcast based on 'breaking' news can also be given higher shelflife with appropriate editorial treatment. This goes against the conventionally understood news value of 'immediacy' which may hold true for other news formats. Additionally, podcasting is considered to be an 'intimate' medium (Berry, 2016) which helps in forming a personal connection with the audience through the informal, conversational content it mostly features. (Swiatek, 2018) All the interviewed journalists mentioned that they try to maintain this conversational tone in their podcast content (elaborated later in 6.3). Hence, selecting topics which would harbour a possibility of conversation becomes crucial.

Additionally, we can't overlook that news values can often be seen less as a reflection of what audience wants, and more as a reflection of the organizational, sociological and cultural norms along with economic factors (Weaver et al., 2007). For example, the decision to create a podcast on a certain topic is often influenced by the perceived image of the organization. The Hindu boasts of being known for its serious, in depth reporting. These journalists want to uphold this organizational image when they choose a topic. Health, education, civic affairs would be most commonly selected beats as they align well with the image. Entertainment hardly features on the Hindu's as well as moneycontrol's podcasts. There is not a single podcast that the Hindu created on the death of a Bollywood celebrity in the recent past. "We have nothing against entertainment. But we are a sensible, nonfrivolous, business oriented website", says the moneycontrol team. Selecting entertainment based topics will be perceived as frivolous and will dilute the organizational image, they worry.

\section{News production: 4.2 Headlining:}

Headlining has always been an essential work practice for journalists, whose earlier function was to adequately and clearly inform the reader what the article was about. (Dijk, 1998) But since many headlines are not read within the context of a newspaper anymore, the function of the headline has shifted. Rubin, Chen, \& Conroy (2015) suggest that the headline needs to make the reader curious as to what the article is about, so that it lures the reader into opening the article. 'The right headline is gold!' exclaimed money control team members. Every interviewed journalist agreed with this opinion, explaining how they often spend up to an hour to decide the right headline of a podcast episode. The knowledge of that day's trending words and themes plays a role here too, with the trending words being included in the headline in order to be optimized for SEO.

The podcasting journalists are aware of the effect that 'unbundling' (Trilling, 2019) of news has had on their practice of headlining. Dissemination of individual news items, supported by social media sharing and news aggregators is the norm of the digital world, where 'whole' of newspaper is not disseminated or consumed. This unbundling of news causes changes in audience's news consumption where they start treating every piece of content separately (Trilling, 2019). One of the interviewed journalists explained: "When you buy a newspaper, you buy the whole paper. And you will possibly read most news stories. Every story need not fight for your attention in order to be consumed. In the digital 
medium, every story has to fight its own battle for consumption and hence, headline will successfully sell that story to you. If you write a news story for the times, the brand of 'times' will automatically help your story to be consumed. What would my podcast do? Since it is separately disseminated, it has no brand to go with. A right headline becomes my brand. Slowly, audience starts recognizing my style through headlines and start liking and consuming those."

A selling and branding tool is a fascinating conceptualization of a headline. It becomes even more important with reference to podcasting, since the podcasts are only audio files, disseminated in a stand-alone manner on the website or through social media. The audience cannot quickly scan through it, unlike the written content. Headline is a tool with which the podcasts vie for audience attention. "The right headline will guide my podcast episode through the maze of Google and Facebook algorithms", said a journalist from the BBC team.

\subsection{Journalistic storytelling}

Most early researches suggest that a good piece of journalism is always supposed to be factual and should not be considered as a narration or an engaging story of some kind. (Zelizer,2004). However, notion is fading away in the recent times, with journalism itself taking a more narrative turn. Journalism has evolved "from the provision of facts to the provision of meaning" (Bardoel, 1996). Steensen (2011) had spoken about the 'Featurization of journalism', stressing on how journalism's social function is being eroded due to this. A latest study examining the content of journalistic podcasts produced during the pandemic (Nee \& Santana, 2021) confirms that more narrative style is employed in the content presentation and this format of journalism is slowly moving away from the erstwhile journalistic norm of 'objectivity' and going more towards interpretative reporting.

While content analysis of the podcasts that these journalists produce can possibly check for the 'narrative turn', it is equally important to know about the shared understanding that journalists have about this and the enactment of its understanding. The interviewed journalists confirmed this while speaking about their practice of producing more narrative, conversational content inspired from or relevant to factual news. "On the day after the union budget, we produced three podcasts, each featuring a character of working man, a working woman and a senior citizen. It delved deeper into typical needs of that specific category and discussed what they may feel about provisions in budget from their perspective. We got many mails saying that audience liked how interesting we had made the explanation of budget provisions for them" said a moneycontrol team member. Informality of presentation and creating conversations around the news of the day is valued in podcasting, say the journalists.

Extending the point of the narrative turn, the journalists also shed light on what perhaps could be called as 'emotional turn' (WahlJorgensen, 2019). More than half of interviewed journalists argued that their practice is different from what was taught to them in J-schools. They iterate that they are not acting as detached observers of society when they conceptualize and produce podcasts. They are rather constructing a nuanced view of society with multiple perspectives; something which a journalist is ought to do in their opinion. "Op-eds have always been doing this in the print medium. Their job was to offer different perspectives on some latest incident or issue. Podcasts are now filling that space", opined a journalist from the Hindu team. This construction of reality is undoubtedly influenced by the subjectivities of the journalist. Since multiple perspectives or multiple versions of reality exist for the journalists, they like to present them in a more open style or have conversations about these different perspectives. The narrative turn then, may be partially attributed to this emotional turn.

And despite these turns, all the interviewed journalists remained convinced about what they practice can be considered as journalism. "We may not be news-givers. We are 'viewsgivers'. But why should that mean that what we do is not journalism?" asked a journalist from the moneycontrol team. In the context of the influx domain of journalism, their shared understanding of their practice should indeed have legitimacy. This may prove to be an example of Zelizer's (2009) conceptualization of "existence of various kinds of journalisms with necessarily multiple facets, definitions, circumstances and functions". 


\subsection{Slow journalism}

The practices of podcasting journalists also display the characteristics of slow journalism. Masurier (2015) elaborates on the characteristics of slow journalism as observed in its self-proclaimed practitioners. Collaboration and investigation in producing content, emergence of different news values, a focus on narrative storytelling elements rather than mechanized style of news presentation, not focusing on beating the competition and avoiding sensationalism were some of the characteristics of the practice of slow journalism. This practice has emerged in response to the contemporary journalism's need for speed, even more pressing in the digital world. The practitioners know that slow journalism can never replace the mainstream speed-driven news, but it intends to provide a critical alternative practice. (Masurier, 2015).

Apart from this resemblance, the interviewed journalists also confirmed that they conceptualize their practice as somewhat of a slow journalism. Indian journalism too is an example of the ever increasing need for speed. In fact, much before the web, the TV journalism in India has been notorious for its constant need of breaking news, frequent sacrifice of accuracy in favor of speed and sensationalizing. In a media landscape that prioritizes instantaneity, the journalists look at podcasting as a clutter breaker. Interestingly, this clutter breaker function is relevant more to a journalist than the audience, say the journalists. For the modern day news worker, dealing with grueling demands of multimedia news production, the professional practice is 'always on'. Engaging in podcast production offers a welcome escape to the journalist. "I otherwise may have been asked to track and post twitter updates of some story. Constant monitoring of feeds, tracking multiple accounts, writing quick copy for SEO and all the jazz. But since I am now a part of podcast team, I get to skip all that chaos!" exclaims one of the journalists in an informal chat.

\subsection{The blown-up newsroom:}

Journalistic production happening outside the physical confinements of a particular newsroom was anyway a common characteristic of the modern day journalism, with journalists reporting from all across the country, the debating guests telecasted live from their own locations, interviews happening on skype etc. The podcasting journalists displayed the 'blown-upness' of newsroom in the following ways: a) the editorial and technology teams sitting in newsrooms at physically different locations, and routinely working on the same episode. b) The podcasts featuring journalists from nonpodcasting teams of the same outlet, often as hosts. This was done to increase the diversity in perspectives and richness of podcast content.

However, the context of pandemic has highlighted and confirmed the blown-up nature of the modern newsroom, particularly journalistic podcasting like never before. Not just has newsroom lost its centrality of existence, but most newsrooms, even as binding structures on a conceptual level have dispersed. All the interviewed journalists shifted to working-from-home owing to the pandemic situation around. The news production, curiously, has stayed intact though. The BBC Marathi team started podcasting during the pandemic itself, whereas the remaining two continued podcasting and increased their output during the pandemic. The listenership has shown tremendous increase, which the journalists take as a validation of their practice. Growth of podcasting in the pandemic times may also indicate that it is not a mere beneficiary of the changing structure, but also a catalyst in the process of old newsroom ways being replaced with new. This may be the case, since the podcasting journalists say that their working practice has changed for foreseeable future.

\section{LIMITATIONS AND SCOPE FOR FURTHER RESEARCH}

The study employs qualitative methodology and works on a small sample size, due to which, the findings of the study may not be generalized to a large population. The pandemic situation also acted as a major limitation in the data collection process. The researcher could not carry out the planned newsroom visits for participant observation and hence had to rely on in-depth interviews of journalists describing their practice. The self-reported data may suffer from several biases like selective memory, selective attributions or exaggeration. The researcher is conscious of these limitations. Newsroom visits in future may be carried out to generate 
more insights. A further study, wider in sample and employing additional quantitative methods could also add more value to these initial findings put forth by this study.

\section{CONCLUSION}

This research attempted studying the practices concerning news selection and production as found in Indian journalistic podcasting. Unique news values seem to be emerging in podcast news selection. The production practice of headlining has achieved paramount importance, since it is conceptualized as a branding and selling tool for a podcast. The journalistic practice of the 'blown-up newsroom' age became apparent, especially in the pandemic context. Journalists were also found to be consciously employing the narrative form of storytelling, which is in contrast with the objectivity norm of journalism and embraces the interpretive turn. Finally, the podcasting journalists were found to understand podcasting as a form of slow journalism' and consciously employing the slow techniques in their practice, conceptualizing podcasts as a necessary break in the modern day news work that is 'always on'.

\section{REFERENCES}

Anderson, C. (2011). Blowing up the newsroom: Ethnography in an age of distributed journalism. In making online news (pp. 151-160). New York: Peter Lang.

Bardoel, J. (1996). Beyond Journalism: A Profession between Information Society and Civil Society. European Journal of communication, 11(3), 283-302. doi:https://doi.org/10.1177\%2F02673231 96011003001

Barnard, S. (2016). 'Tweet or be sacked': Twitter and the new elements of journalistic practice. Journalism, 17(2), 190-207.

doi:https:/ /doi.org/10.1177\%2F14648849 14553079

Berry, R. (2015). A Golden Age of Podcasting: Evaluating Serial in the context of podcast histories. Journal of Radio and Audio media, 22(2), 170-178
Berry, R. (2016). Part of the establishment: Reflecting on 10 years of podcasting as an audio medium. Convergence: The international journal of research in new media technologies, 22(6), 661-671. doi:https:// doi.org/10.1177\%2F13548565 16632105

Coddington, M. (2019). Aggregating the News: Secondhand Knowledge and the Erosion of Journalistic Authority. New York: Columbia University press.

Couldry, N. (2004). Theorising media as practice. Social Semiotics, 2, 115-132. doi:https://doi.org/10.1080/1035033042 000238295

Coward, R. (2013). Speaking personally: The rise of subjective and confessional journalism. Macmillan Science \& Educ. UK: United Kingdom.

D.H.Weaver, Beam, R. A., Brownlee, B. J., Voakes, P. S., \& Willhoit, G. C. (2007). The American journalist in the 21st century: U.S. news people at the dawn of a new millennium. New York: Routledge.

Deuze, M., \& Witschge, T. (2018). Beyond journalism: Theorizing the transformation of journalism. Journalism, 165-181.

Dijk, T. V. (1998). Opinions and ideologies in the press. In A. Bell, \& P. Garrett, Approaches to Media discourse. Oxford: Blackwell.

Galtung, J., \& Ruge, M. (1965). The Structure of Foreign News: The Presentation of the Congo, Cuba and Cyprus Crises in Four Norwegian Newspapers. Journal of peace research, 2(1), 64-90.

Gherardi, S. (2009). Practice? It's a matter of taste! Management Learning, 40(5), 535550.

Golding, P. (1979). Making the news. London: Longman.

Hallin, D. (1992). The Passing of the "High Modernism" of American Journalism. The Journal of communication, 42(3), 14-25. doi:https://doi.org/10.1111/j.14602466.1992.tb00794.x

Haniztsch, T. (2007). Deconstructing Journalism Culture: Toward a Universal Theory. Communication Theory, 17, 367385. 
Harcup, T., \& O'Neil, D. (2017). What is news?: News values revisited )again). journalism studies, 1470-1488. doi:https:/ / doi.org/10.1080/1461670X.20 16.1150193

Herman, E., \& Chomsky, N. (1989). Manufacturing Consent. Pantheon books, inc.

Hermida, A. (2010). Twittering the news: emergence of ambient journalism. journalism practice, 297-308.

Hermida, A. (2019). The existential predicament when journalism moves beyond journalism. Journalism, 177-180. doi:https://doi.org/10.1177\%2F14648849 18807367

Karlsson, M., Clerwall, C., \& Nord, L. (2018). The public doesn't miss the public. Views from the people: Why news by the people? Journalism, 19(5), 577-594. doi:https:/ / doi.org/10.1177\%2F14648849 17694399

Larson, S. (2015, February 20). Serial, Podcasts, and Humanizing the News. Retrieved from The New Yorker: https://www.newyorker.com/culture/s arah-larson/serial-podcasts-humanizingnews

Lindgren, M. (2016). Personal narrative journalism and podcasting. Radio Journal: International Studies in Broadcast $\mathcal{E}$ Audio Media, 23-41.

Mandavia, M. (2020, March 27). Podcasts find their voice during CoVid-19 pandemic. Economic Times. Retrieved from https:/ / economictimes.indiatimes.com/t ech/internet/podcasts-find-their-voiceduringpandemic/articleshow/74836198.cms?fro $\mathrm{m}=\mathrm{md}$

Manning-White, d. (1950). The "Gate Keeper": A Case Study in the Selection of News. journalism $\mathcal{E}$ Mass Communication Quarterly, 27(4), 383-390.

Masurier, M. L. (2015). What is Slow Journalism? Journalism Practice, 138-152.

McLess, L. (2013). A Postcolonial Approach to Urban Studies: Interviews, Mental Maps, and Photo Voices on the Urban Farms of Dar es Salaam, Tanzania. The Professional Geographer, 65(2), 283-295.
Morris, J. W., \& patterson, e. (2015). Podcasting and its Apps: Software, Sound, and the Interfaces of Digital Audio. Journal of radio and Audio media, 22(2),

220-230. doi:https:/ / doi.org/10.1080/19376529.20 15.1083374

Nee, R., \& Santana, A. (2021). Podcasting the Pandemic: Exploring Storytelling Formats and Shifting Journalistic Norms in News Podcasts Related to the Coronavirus. Journalism practice. doi:https://doi.org/10.1080/17512786.20 21.1882874

Neheli, N. B. (2018). News by numbers: the volution of analytics in journalism. digital journalism, 1041-1051.

Nelson, J. (2019). The next media regime:The pursuit of 'audience engagement' in journalism. Journalism, 1-18.

Newman, N., \& Gallo, N. (2019). News Podcasts and the Opportunities for Publishers. United Knigdom: Reuters Institute.

Newman, N., Fletcher, R., Kalogeropoulos, A., Levy, D., \& Nielsen, R. k. (2017). Reuters Institute digital News report. United Kingdom: Reuters Institute. Retrieved from https://reutersinstitute.politics.ox ac.uk/sites/default/files/Digital\%20Ne ws\%20Report\%202017\%20web_0.pdf

PriceWaterhouseCoopers. (2020). Global Entertainment \& Media Outlook 2020-2024 India. United Kingdom: Price Waterhouse Coopers.

Raetzsch, C. (2015). Innovation through practice: Journalism as a structure of public communication. journalism Practice, 9(1), 65-77.

Rosen, J. (2012). The people formerly known as the audience. In The social Media Reader (pp. 13-16). New York: NYU Press.

Rubin, V., Chen, y., \& Conroy, N. (2015). Deception detection for news: Three types of fakes. Proceedings of the Association for Information Science and Technology (pp. 1-4). Wiley.

Saltzis, K. (2012). Breaking News Online. Journalism practice, 702-710. doi:https:/ /doi.org/10.1080/17512786.20 12.667274 
Santana, A., \& Dozier, D. (2019). Mobile Devices Offer Little In-depth News: Sensational, Breaking and Entertainment News Dominate Mobile News Sites. Journalism Practice, 1106-1127. doi:https:/ / doi.org/10.1080/17512786.20 19.1588144

Schatzki, T., Knorr Cetina, K., \& Savigny, E. (2001). The practice turn in the contemporary theory. London: Routledge.

Schlesinger, P. (1978). Putting 'reality' together. COnstable.

Shoemaker, P., \& Reese, S. (1996). ediating the Message: Theories of Influences on Mass Media Content. New York: Longman.

Spyridou, L.-P., Matsoita, M., Veglis, A., Kalliris, G., \& Dimoulas, C. (2013). Journalism in a state of flux: Journalists as agents of technology innovation and emerging news practices. International Communication Gazzette, 75(1). doi:https://doi.org/10.1177\%2F17480485 12461763

Steensen, S. (2011). The Featurization of Journalism. Nordicom Review, 32(2), 49-61. doi:https://doi.org/10.1515/nor-20170112

Steensen, S. \& Westlund, O. (2020) What is Digital Journalism Studies? Routledge, New York.

Swiatek, L. (2018). The podcast as an intimate bridging medium. In D. Llinares, N. Fox, \& R. Berry, Podcasting: New aural cultures and digital media (pp. 173-187). Palgrave McMillan, Cham.

Trilling, D. (2019). Conceptualizing and Measuring News Exposure as Network of Users and news items. In C. Peter, T. Naab, \& R. Kuehne, Measuring Media Use and Exposure:Recent Developments and Challenges (pp. 297-317). Herbert von Halem Verlag.

Tuchman, g. (1978). Making news : a study in the construction of reality. New York: Free Press.

Turnstall, J. (1971). Journalists at work: specialist correspondents: Their news organizations, news sources, and competitor-colleagues. Constable.

$\mathrm{Vu}, \mathrm{H}$. T. (2014). The online audience as gatekeeper: The influence of reader metrics on news editorial selection. Journalism, 15(8), 1094-1110. doi:https:/ / doi.org/10.1177\%2F14648849 13504259

Wahl-Jorgensen, K. (2019). An Emotional Turn in Journalism Studies? Digital Journalism, 175-194.

Witschge, T., \& Harbers, F. (2018). Journalism. Handbooks of Communication Science (HoCS). Berlin: Walter de Gruyter $\mathrm{GmbH}$ \& Co KG.

Zelizer, B. (2004). Taking Journalism Seriously: news and the Academy. California: Sage publication, Inc. doi:http://dx.doi.org/10.4135/97814522 04499

Zelizer, B. (2009). The Changing Faces of Journalism: Tabloidization, Technology and Truthiness. Routledge.

Zompa, T. (2021, January 30). Self-love $\mathcal{E}$ storytelling - How India saw a podcast boom in the pandemic year 2020. Retrieved from The Print: https:/ / theprint.in/features/self-lovestorytelling-how-india-saw-a-podcastboom-in-the-pandemic-year2020/593810/ 